\title{
New Trends to Improve the Raw Materials of Automotive Parts/Spare Parts
}

\author{
Mahmoud Mohamed Ahmed Sayed \\ Mechanical Engineering Department, Canadian International College, Cairo, Egypt \\ Email address: \\ m_m_sayed@cic-cairo.com

\section{To cite this article:} \\ Mahmoud Mohamed Ahmed Sayed. New Trends to Improve the Raw Materials of Automotive Parts/Spare Parts. American Journal of \\ Mechanics and Applications. Vol. 6, No. 1, 2018,pp. 7-11. doi: 10.11648/j.ajma.20180601.12
}

Received: December 28, 2017; Accepted: January 17, 2018; Published: February 7, 2018

\begin{abstract}
The automotive industry is one of the important industries which affected by raw materials of parts/spare parts. This work is applied research on the automotive products, such as main parts, and spare parts. The automotive products meet lot of problems, which come from certain causes such as environmental conditions. This work faces these problems and solves it, by taking some actions. Selecting raw materials which represent main causes of the problems and treatment it. This work uses analytical tool (Root - Cause Effect) to find out the root causes. Also, this work used new trends to improve the performance of raw material which uses in manufacturing of products such chemical treatment.
\end{abstract}

Keywords: Raw Materials, Root - Cause Effect, Material in Manufacturing

\section{Introduction}

Automotive products, parts, and spare parts are facing severe conditions. Then, raw material is the corner stone to provide suitable products. Researches, designers, and manufacturers focus on selecting and treatment of raw materials.

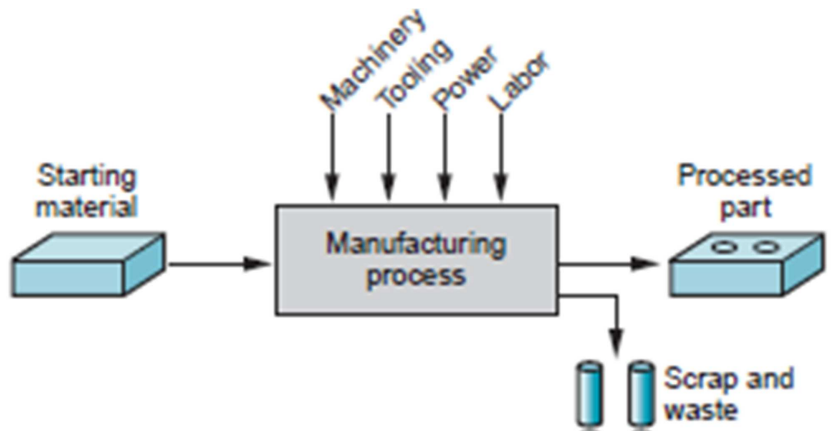

Figure 1. Manufacturing process.

raw materials exist throughout the entire process of the life cycle of products. Research into the reduction, replacement, and recycling of raw materials has to start from analysis into the entire life cycle of the products and find the existing problems in materials utilization, in order to innovate and raise the efficiency of raw material utilization [1]. The material has been made more valuable through the manufacturing operations performed on it. The key point is that manufacturing adds value to the material by changing it, shape or properties, or by combining it with other materials that have been similarly altered. Figure 1, represents manufacturing as a technical process, which indicates the starting materials (raw material) as input to the manufacturing process [2].

Raw materials are fundamental to Europe's economy, growth and jobs and they are essential for maintaining and improving our quality of life. Recent years have seen a growth in the number of materials used across products. Securing reliable, sustainable and undistorted access of certain raw materials is of growing concern within the EU and across the globe. Raw materials have a high economic importance to the EU combined with a high risk associated with their supply [3].

In industry, raw materials represent cornerstone of manufacturing process. This work indicates in Figure 2, the manufacturing process which considered the raw material as main element. The designers choose the raw material according: customer needs such as: specification, and controls. 

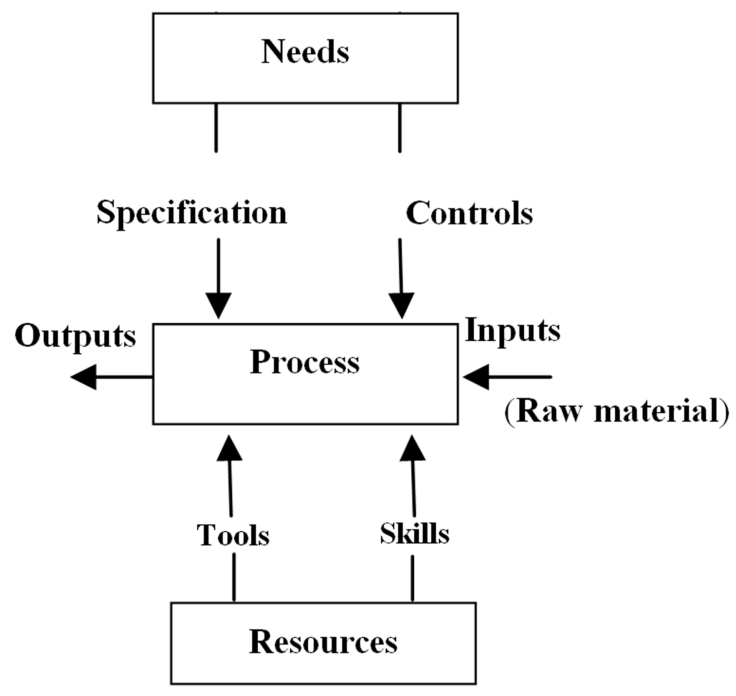

Figure 2. Main elements of manufacturing process.

\section{Raw Material in Manufacturing}

Most engineering materials can be classified into one of three basic categories: metals, ceramics, and polymers. Their chemistries are different, their mechanical and physical properties are different, and these differences affect the manufacturing processes that can be used to produce products from them. In addition to the three basic categories, there are composites-nonhomogeneous mixtures of the other three basic types rather than a unique category [1-3].

\subsection{Engineering Manufacturing}

Many applications use engineering materials, especially in automotive field. In Figure 3, the engineering materials divided into four groups: metals, ceramics, polymers, and composites. One of the main groups of engineering materials is metals which classify into: ferrous and nonferrous.

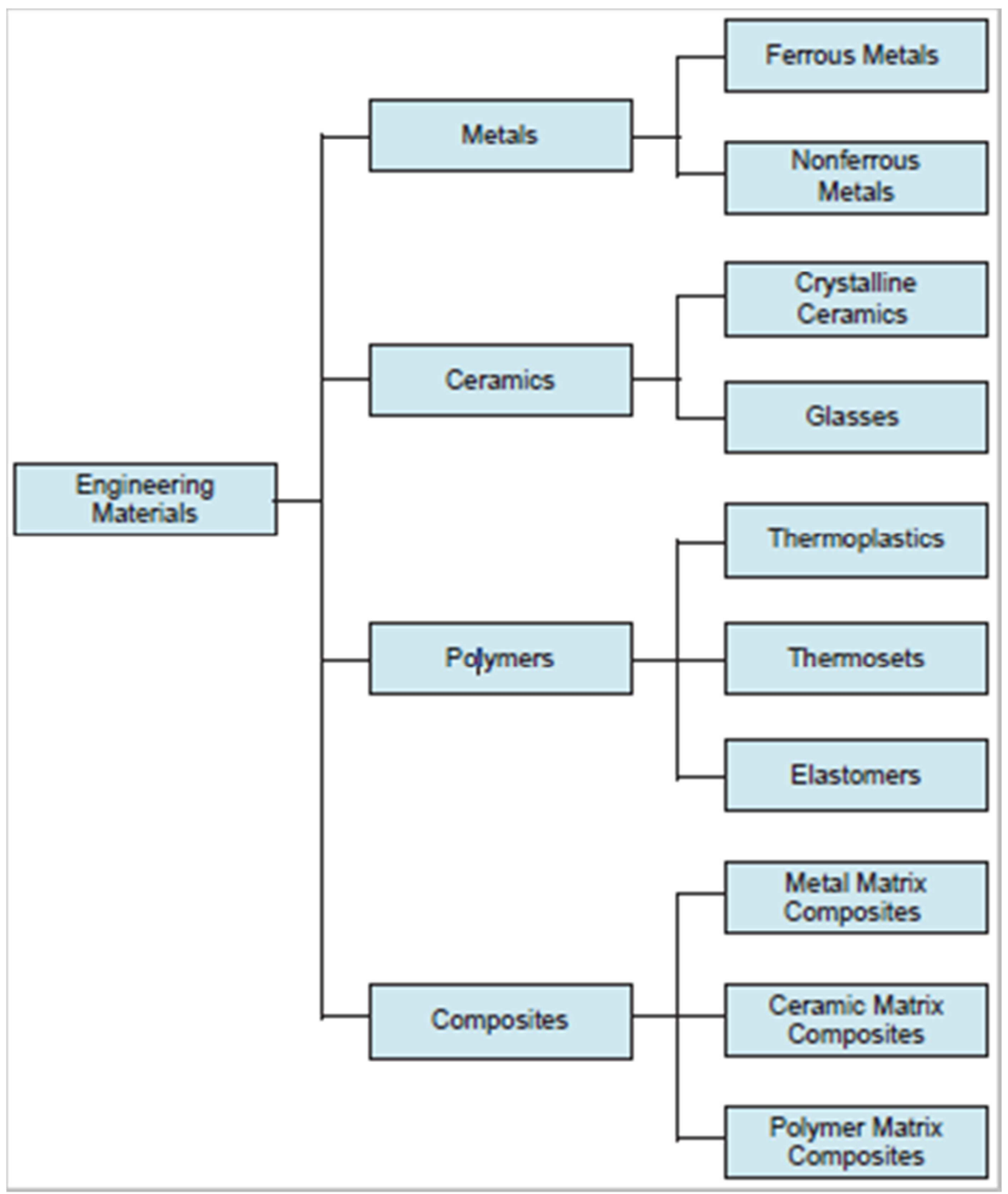

Figure 3. Classification of materials.

Nonferrous metals and alloys cover a wide range, from the more common metals (such as: aluminum, copper,...) to high-strength, high-temperature alloys (such as those of tungsten, tantalum, ...). Metal alloys require a wide variety of properties to improve their manufacturing characteristics, [4]. 


\subsection{Metals in Manufacturing}

A metal which using in automotive products, parts, and spare parts are usually consists of more than one element. The study indicates raw materials (metals and alloys) classified into two basic groups: ferrous and nonferrous (include metal elements and alloys not based on iron). The most important metals in the nonferrous group are: copper, aluminum, and zinc, and their alloys. The most of the nonferrous metals have good properties other than mechanical that make them ideal for applications. This work considered two main factors have a great impact on the performance of parts: corrosion and wear. Corrosion of parts happens due to environmental conditions. Then, in this work will indicate the required ways to avoid or eliminate the corrosion.

\section{Research Methodology}

Corrosion is the main problem, which faces producers and users. This is so due to certain reasons such as: specifications of raw materials, during manufacturing operations, and working processes. This research insists on raw materials and how to increase their performance. Also, this work introduces a methodology to avoid the causes of the corrosion as follows:

a) Design phase: Specifications of raw materials ( chemical treatment)

b) Production phase: Manufacturing process (shaping, soldering, painting,...)

c) Working phase: Effect of environmental conditions (corrosion resistance...)

This work focuses on the reasons of the problems to solve some of the problems which meet the products throughout customers, employees, and suppliers as follows:

a) Customers: Tell about behavior of the products and effect of environmental conditions on it.

b) Employees: Tell about the behavior of raw materials (metals - treatments...) during production and effect of chemical activities (solvents, painting, treatment,..) on the products.

c) Suppliers: Tell about the new trends to improve the performance of raw materials.

This work uses Root - Cause Effect as tool to depict the causes of problems which effects on the product as shown in Figure 4.

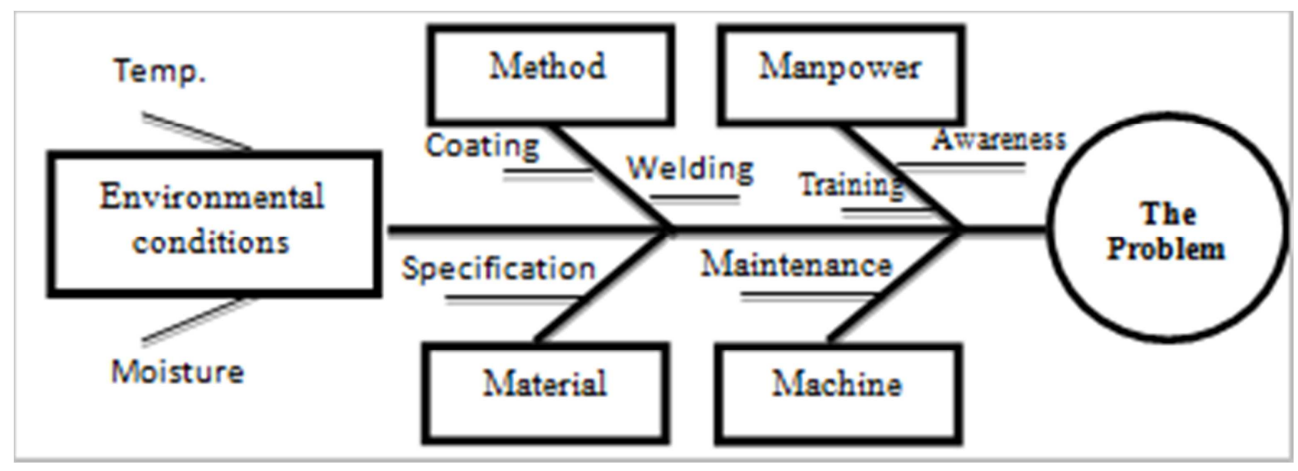

Figure 4. Root-Cause Effect diagram.

Figure 4, Indicates the causes of any problem which comes due to; manpower (lack of training, misunderstanding, or awareness...), machine (maintenance, setting or calibration,...), method (coating, welding,..), and raw material (specifications, treatment..). This work monitors the behavior of raw materials (metals - chemical treatment...) which receiving from suppliers until submit to customers.

\section{New Trends to Improve the Performance of Raw Material}

Corrosion is the main problem which attacks the products due to environmental conditions. The surface of metals suffer from corrosion. The major categories of surface processing operations are: cleaning, surface treatments, and coating and thin film deposition. Cleaning refers to industrial cleaning processes that remove contaminants and include both chemical and mechanical cleaning methods. Surface treatments are mechanical and physical operations such as improving its finish or impregnating it with atoms of a foreign material to change its chemistry and physical properties. This work represents new trends to improve the performance of raw material such as: coating, cleaning, etc..

\subsection{Coating}

Most new products (using coating of raw material) are based on ingredients from renewable or sustainable resources. The reliance on fossil fuels as sources of raw materials for coatings is shifting to a reliance on natural products, with suppliers also being sensitive to the need to not affect the use of these materials in the human food chain [5].

Coating and thin film depositions include various processes that apply a layer of material to a surface. Products made of metal are almost always coated such as: painting, or other process. Principal reasons for coating are to improve the performance: provide corrosion protection, enhance product appearance, increase wear resistance and/or reduce friction of the surface, increase conductivity, prepare a metallic surface for subsequent processing, and rebuild 
surfaces worn or eroded during service.

\subsection{Industrial Cleaning Process}

Work parts must be cleaned one or more times during their manufacturing sequence. Chemical and/or mechanical processes are used to accomplish this cleaning. Chemical cleaning methods use chemicals to remove unwanted matters from the work piece surface. Mechanical cleaning involves removal of substances from a surface by mechanical operations of various kinds. These operations often serve other functions such as enhancing surface properties. There are two main types of cleaning chemical and mechanical cleaning.

\subsection{Chemical Cleaning}

Combinations of corrosion inhibitors are extensively used in industry. When two or more corrosion inhibitors are used, the inhibition efficiency of the mixture may be improved. Factors such as concentration of the solution, time of immersion and solvent (de-ionized water, and ethanol) were tested [6]. The corrosion inhibitor should form a complex with copper, resulting in a polymeric layer. These polymer formations are considered to have the most suitable structure, because they develop a barrier between the metal substrate and its environment. The polymer structure should be thick, dense and without voids in order to stop further oxidation of metal [7]. The mechanistic aspects of the corrosion inhibition are explained by the results of electrochemical and surface analytical studies [8].

This work indicates some of the important reasons why manufactured parts or spare parts (products) must be cleaned as follows:

a) prepare the surface for subsequent industrial processing, such as a coating application or adhesive bonding;

b) improve hygiene conditions for workers and customers;

c) remove contaminants that might chemically react with the surface; and

d) Enhance appearance and performance of the product.

\subsection{Impact of Composite Materials}

The automotive industry have accepted composite materials in their manufacturing. The choice of composites is a tradeoff between cost and performance. Composite design, analysis, manufacturing tools will sustain for reducing cycle time, costs, and improve the quality of parts/spare parts being manufactured, [9-10].

\section{The Results and Discussion}

The research took 12 months (the sample under investigation: raw materials and parts / products)

\subsection{Procedure of Research}

It divided into three periods: a) $1^{\text {st }}$ period: evaluate and monitor the current situation, find out the main problems and analysis it

b) $2^{\text {nd }}$ period: apply a certain modification

c) $3^{\text {rd }}$ period: monitor and evaluate the results.

\subsection{Samples of Research}

This work took samples (from raw materials and products) as follows:

a) In indoor (inside the factory through production stages) and outdoor (in three different places according the environmental conditions)

b) During study of some defects (corrosion) which analyzed.

c) Most of problems come from the type of raw material, and chemical treatment which uses during production, and the methods of preparing and using the chemical solvents.

d) Despite the use of chemical solvents appropriate some of the problems which appear because of timekeeping of products and its presence with solutions chemical solvents.

\subsection{The Results}

This section indicates the results that were obtained indoor (in factory, which production process through three stages) and outdoor (working process in three different area). This work collected data and analyzed it throughout three periods, which summarized in tables 2,3 .

Table 1. Number of defects (Before modification).

\begin{tabular}{lllll}
\hline \multirow{2}{*}{ Place } & \multirow{2}{*}{ Stage or area } & \multicolumn{3}{l}{ Number of defects (Before) } \\
\cline { 3 - 5 } & & Sample 1 & Sample 2 & Sample 3 \\
\hline \multirow{3}{*}{ Indoor } & $1^{\text {st }}$ Stage & 21 & 22 & 19 \\
& $2^{\text {nd }}$ Stage & 19 & 20 & 16 \\
& $3^{\text {rd }}$ Stage & 18 & 21 & 11 \\
\multirow{4}{*}{ Outdoor } & Area (A) & 25 & 23 & 26 \\
& Area (B) & 12 & 11 & 9 \\
& Area (C) & 6 & 5 & 6 \\
\hline
\end{tabular}

Table 2. Number of defects (After selecting and treatment of raw materials).

\begin{tabular}{lllll}
\hline \multirow{2}{*}{ Place } & \multirow{2}{*}{ Stage or area } & \multicolumn{3}{l}{ Number of defects (After) } \\
\cline { 3 - 5 } & & Sample 1 & Sample 2 & Sample 3 \\
\hline \multirow{3}{*}{ Indoor } & 1st Stage & 1 & 1 & 1 \\
& 2nd Stage & 3 & 2 & 1 \\
\multirow{4}{*}{ Outdoor } & 3rd Stage & 2 & - & 1 \\
& Area (A) & 3 & 2 & 1 \\
& Area (B) & 1 & - & 1 \\
\hline
\end{tabular}

From tables $(1,2)$, it is notes the number of defects decreases due selecting of suitable raw materials and time of treatment. In area (A) the number of defects is more than others, because area (A) near from the sea (effect of environmental conditions). During study the teamwork took a certain activities (selecting of the specification of raw materials, and increase the awareness of engineers and workers such as: temperature of working area $\left[25-30^{\circ} \mathrm{C}\right.$ ) and stirring the chemical solvents with a certain speed). 


\section{Conclusions}

Some organizations and companies attempt to achieve their goal (improve productivity, customer satisfaction, and market share) throughout improving the performance of raw materials, which has great impact on the final product. This work studies the improvement of performance of raw materials and avoids the corrosion which represents the main problem and makes analysis to prevent causes occurred. This work uses new trends (special chemical treatment) to win new properties for raw materials. This work focuses on some points to avoid or eliminate the causes of defects of products and spare parts:

a) Using the chemical treatment (types of solvent depends on the types of raw materials).

b) Select the suitable raw materials to confirm the specifications.

c) Monitoring the products

\section{References}

[1] Tong Qiu, Raw materials use reduction, replacement, and recycling, Environment and development, Vol. 11, 2012.
[2] Mikell P. Groover, Fundamentals of modern manufacturing: materials, processes and systems, John Wiley \& Sons, Inc., 2010 .

[3] Report on critical raw material for the EU, May 2014.

[4] S. Kalpakjian and Steven R. Schmid, Manufacturing Engineering and Technology, Prentice Hall 2009.

[5] New technology Coatings for Corrosion Control, A JPCL eBook, Technology Publishing Company, Pittsburgh, PA., 2012.

[6] S. Golfomitsou and J. Merkel, Synergistic effects of corrosion inhibitors for copper and copper alloy archaeological artefacts, National Museum of Australia, 2012.

[7] Robert B. Faltermeier, A corrosion inhibitor test for copperbased artifacts, Studies in Conservation 44, 1999, pp. 121-128.

[8] B. V. Rao, and B. Sreedhar, Corrosion protection of copper by self-assembled monolayers, Indian Journal of Chemical Technology, Vol. 16, 2009, pp. 25-31.

[9] Dušan Sabadka, Application potential of composite materials in automotive industry, Transfer inovácií, 2015.

[10] Shama Rao N, et., Automotive Mega Trends USA, Michigan, Mar 17, 2015. 